\title{
Olefin reduction promoted by an ionically-tagged iron catalyst
}

\author{
Marcelo R. dos Santos ${ }^{\star a}$, Júlia R. Diniz ${ }^{a}$, Aline M. Arouca ${ }^{a}$, Alexandre F. Gomes ${ }^{b}$, \\ Fabio C. Gozzo ${ }^{b}$, Paulo A. Z. Suarez ${ }^{a}$ and Brenno A. D. Neto ${ }^{a}$. \\ ${ }^{a}$ Laboratory of Medicinal and Technological Chemistry, Institute of Chemistry - Brasilia university (UnB), DF. \\ ${ }^{\mathrm{b}}$ Institute of Chemistry, State university of Campinas - Campinas, SP. \\ *marcelotigre@gmail.com
}

Keywords: olefin reduction, ionically-tagged, iron complex.

\section{INTRODUCTION}

The development of new, sustainable, efficient, selective and cheap catalysts is a fundamental goal in the modern chemistry. In this sense, the use of non-toxic and environmentally bearable metals such as iron may become a viable alternative to rare and expensive catalytic systems that use precious-metal such as palladium, rhodium, iridium and other metals. ${ }^{1}$ Herein, it is presented the use of a novel ionically-tagged iron catalyst as the promoter of $\mathrm{C}=\mathrm{C}$ reduction.

\section{RESULTS AND DISCUSSION}

The novel iron complex was synthesized as described in Scheme 1.

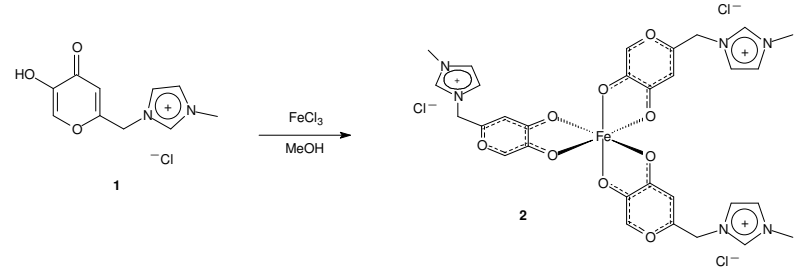

Scheme 1. Synthesis of the ionically-tagged Fe-complex.

Using catalyst 2 supported in $\mathrm{BMI} \cdot \mathrm{NTf}_{2}$, we were able to perform the olefin reduction just by adding methanol into the reaction media, with $15 \mathrm{~atm}$ of synthetic air and $90{ }^{\circ} \mathrm{C}$ of temperature during a period of $24 \mathrm{~h}$ (Scheme 2).

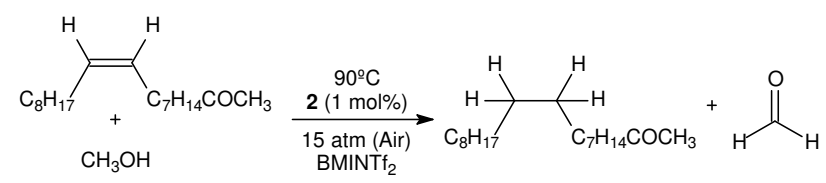

Scheme 2. Olefin reduction by catalyst 2 .

Methyl oleate was reduced affording the desired product in $85 \%$. Recycling reactions were performed and the activity of the ionically-tagged iron catalyst 2 remains unchanged even after 10 runs. Moreover, no catalyst leaching was noted by ICP-AES analysis.
Based in these and others obtained results, it is proposed the following catalytic cycle, as seen in Scheme 3.

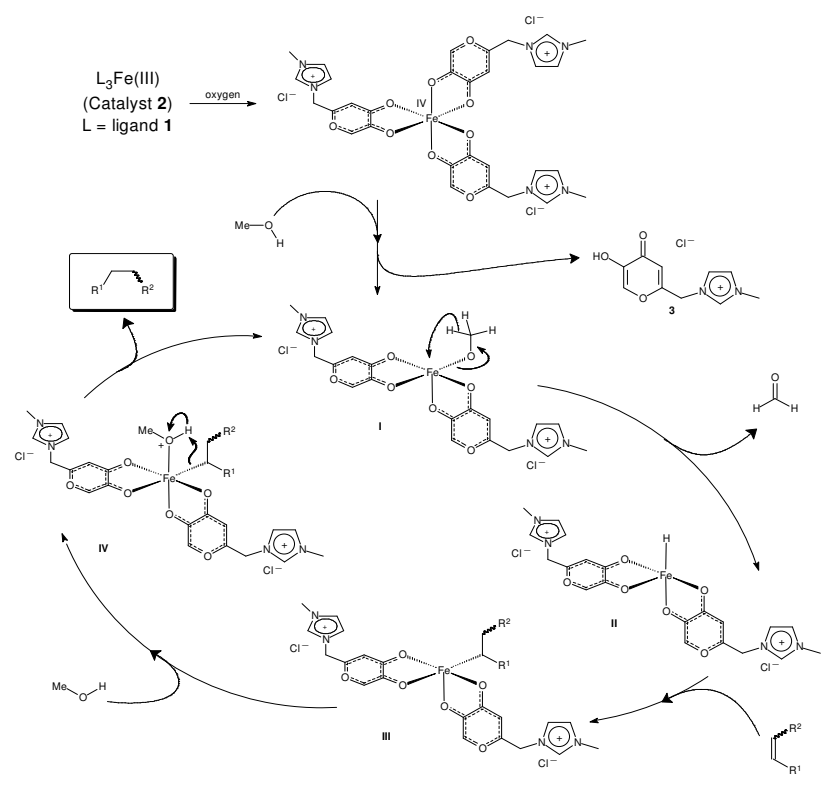

Scheme 3. Catalytic cycle for new olefin reduction.

\section{CONCLUSION}

A new catalytic method using an iron complex to reduce $\mathrm{C}=\mathrm{C}$ double bonds was successfully developed and ten recycling reactions could be performed showing no loss of its activity. A plausible mechanistic cycle was proposed to explain the new reaction.

\section{ACKNOWLEDGEMENTS}

Capes, CNPq and FAPDF for partial financial support.

\section{REFERENCES}

${ }^{1}$ Driller, K. M.; Klein, H.; Jackstell, R.; Beller, M. Angew. Chem., Int. Ed. 2009, 48, 6041-6044. 